\title{
Substance Use Duration Units
}

National Cancer Institute

\section{Source}

National Cancer Institute. Substance Use Duration Units. NCI Thesaurus. Code C83162.

The unit of measure for the period of time over which substance usage occurs. 